\title{
INOVAÇÃO EM MODELO DE NEGÓCIOS: FORMA E CONTEÚDO
}

David Kallás davidk@insper.edu.br

Professor do Instituto de Ensino e Pesquisa - São Paulo - SP, Brasil

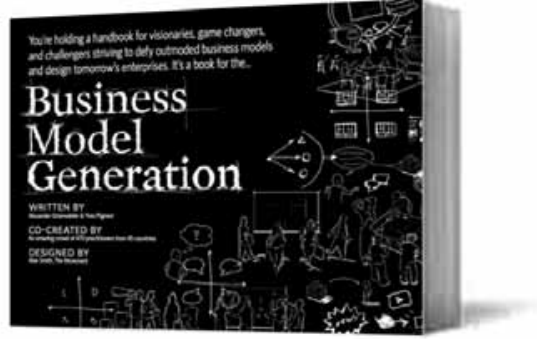

\section{BUSINESS MODEL GENERATION}

Alexander Ostewalder; Yves Pigneur. Hoboken: John Wiley \& Sons, Inc., 2010. 278 p.

"Você está segurando um livro para visionários, inovadores e revolucionários que se esforçam para desafiar os modelos de negócios ultrapassados e projetar os empreendimentos de amanhã." É assim que começa o ousado, inovador e pretensioso livro Business Model Generation. A inovação já começa na sua confecção. O livro é um desdobramento da tese de doutorado de Alex Osterwalder. Ele e Yves Pigneur lançaram a ideia original na internet e contaram com a colaboração de mais de 470 pessoas em 45 países, inclusive no Brasil, para finalizar a obra. Todos os colaboradores recebem os devidos créditos, de acordo com sua ordem de inscrição na iniciativa. Porém, sem ordem alfabética, fica difícil buscar os nomes na lista. Outra inovação importante está na forma do livro, diferente dos modelos tradicionais. As dimensões não são convencionais, e os autores contaram com os serviços de design de Alan Smith para deixar o livro com visual atrativo e intencionalmente fora do padrão.

A motivação pelo tema, segundo os autores, são a superficialidade e a divergência de entendimentos sobre o conceito "modelo de negócios”. Em pesquisa publicada em 2005, os autores mencionam ter recebido, entre 62 respondentes, 54 definições diferentes para o tema. Por meio de pesquisa léxica em artigos acadêmicos com peer review, identificaram também que, apesar de ter aparecido pela primeira vez em um artigo acadêmico em 1957, o termo ganhou destaque somente na década de 1990, coincidentemente com a ascensão da internet, das empresas ponto.com e da Nasdaq. A origem do termo, portanto, possui relação com tecnologia.

Parte dessa relação deriva do fato de que as raízes do conceito estão baseadas na economia dos custos de transação. Basicamente, a rápida evolução tecnológica causou uma dramática redução nos custos de transação, fazendo com que os limites das empresas se tornassem cada vez mais tênues. O conceito foi bastante trabalhado, desde sua conceituação, taxonomia e componentes, até a definição de padrões e aplicação. Os autores basearam-se em trabalhos anteriores desenvolvidos, com destaque para Managing the Digital Enterprise: Business Models on the Web, de Rappa (North Carolina State University, 2001); Business Models for Electronic Markets, de Timmers (Journal on Electronic Markets, 1998); Leading the Revolution, de Hamel (Harvard Business School Press, 2000); e Value Creation in e-Business, de Amit e Zott (Strategic Management Journal, 2001). Outra referência importante para Osterwalder e seus colegas é o balanced scorecard de Kaplan e Norton (Harvard Business Review, 1992; 2000), tanto por conta do desenho visual do mapa estratégico quanto da divisão das perspectivas de negócio. Os autores, entretanto, buscaram aumentar a granularidade das quatro perspectivas do balanced scorecard para um modelo com mais perspectivas (ou, como preferem colocar, mais blocos).

O conteúdo traz interessantes contribuições. Talvez a maior delas seja a de conseguir congregar conceitos importantes de estratégia e inovação em um modelo simples e 
visual, chamado de Business Model Canvas. Trata-se de uma ferramenta para descrever como uma organização cria, entrega e captura valor ou, em outras palavras, descrever o seu modelo de negócios. Aparentemente despretensioso, o canvas é composto de nove blocos cuidadosamente selecionados e organizados. Cada um desses blocos foi mencionado por pelo menos dois dos autores anteriormente citados, em seus respectivos estudos sobre modelos de negócios. Os blocos carregam conceitos importantes e conhecidos da comunidade acadêmica, porém pouco conectados entre si na literatura, como recursos (oriundos da Resource-Based View) e atividades-chave (oriundos da Economia Industrial). O modelo lembra também o diamante proposto por Hambrick e Fredrickson no clássico artigo Are you sure you have a strategy? (Academy of Management Executive, 2001), embora apresente elementos adicionais e não contemple as ondas de implementação da estratégia.

O método baseia-se nos princípios do visual thinking e permite que as pessoas conversem sobre os modelos de negócio. Em outras palavras, é uma plataforma para diálogo que se propõe a apoiar dois tipos de negócios: os existentes e os novos. A organização da obra também chama a atenção pela simplicidade e objetividade, bem como pelo abundante uso de exemplos atuais, com destaque para empresas com alto uso de tecnologia em suas propostas de valor.

Entretanto, apesar de trabalharem bem os conceitos, os autores pecam ao não citar no livro as referências que usaram como bases para a montagem do modelo. É aceitável que não haja um detalhamento de cada um dos elementos do modelo, por conta de restrições de tamanho e espaço no livro. En- tretanto, indicações de fontes dos conceitos usados seriam úteis a leitores interessados em aprofundar seus estudos em temas como segmentação de mercado, proposta de valor e alianças estratégicas, somente para citar alguns exemplos. Aos interessados, é necessário recorrer à tese de Ostewalder e aos artigos acadêmicos já publicados pelos autores.

O livro está estruturado em cinco capítulos. O primeiro deles apresenta a definição do modelo de negócios e introduz os conceitos básicos de cada um dos nove blocos que compõem o canvas, finalizando com o exemplo do modelo de negócios do iPod/iTunes da Apple.

O capítulo 2 apresenta a decomposição de alguns padrões de modelos de negócios, a exemplo de outros autores que historicamente propuseram classificações de estratégias genéricas. São propostos e exemplificados os padrões de empresas desagregadas (empresas de Telecom), cauda longa (Facebook, Lego), plataformas multilaterais (eBay, Visa), gratuito (Skype, Google) e aberto (P\&G, GlaxoSmithKline).

No terceiro capítulo, os autores descrevem e exploram seis técnicas para o desenho de modelos inovadores: reflexões de clientes, ideação (ideation), pensamento visual, prototipação, storytelling e cenários. Cada técnica é apresentada com uma história contando como se deu sua aplicação.

No capítulo 4, são propostas formas de reinterpretar conceitos tradicionais de estratégia a partir das lentes do canvas. Nesse capítulo, os autores indicam como utilizar seu modelo para aprimorar a utilização de ferramentas como Análise Ambiental, Análise Setorial (cinco forças), Análise SWOT e Estratégia do Oceano Azul. Apesar de apresentar algumas técnicas interessantes, como a análise interna por meio do canvas, esse capítulo exagera na tentativa de vincular seu modelo com todos esses conceitos já consagrados.

O capítulo 5 apresenta uma proposta de processo para a criação ou inovação em modelos de negócio, dividido em cinco fases: mobilizar, entender, desenhar, implementar e gerenciar. Para cada etapa, são propostas as atividades, fatores críticos de sucesso e principais pontos de risco.

A obra encerra-se com uma rápida apresentação de cinco tópicos a serem explorados em possíveis obras futuras. Primeiramente, comenta a utilização do canvas no setor público e no terceiro setor. Em seguida, discorre sobre o apoio de ferramentas de prototipagem para os esforços de geração de modelos de negócios. Posteriormente, discute a relação entre modelos de negócios e planos de negócios. Em seguida, endereça assuntos críticos da implementação de modelos de negócios e, finalmente, examina como alcançar alinhamento entre o modelo de negócios e tecnologia da informação.

De modo geral, a leitura compensa, desde o conteúdo, que consegue ser inovador quando organiza conceitos existentes de maneira diferente, e principalmente na forma, agradável, visual e objetiva. E, mais do que ler, vale a pena pegar um bloco de post-it e sair por aí desenhando e criando modelos de negócios.

Meus agradecimentos a Luis Eduardo Carvalho, um dos 470 colaboradores e revisor técnico da tradução do livro para o português, pelas valiosas contribuições. 